\title{
A Review of Renewable Energy Development in PJM
}

\author{
Zhenyu Fan
}

\author{
IEEE Senior Member, PJM Interconnection, USA
}

\begin{abstract}
As one of the world's largest grid operators, PJM interconnection in the United State leads and promotes renewable energy and greener grid. The growth of solar, wind and other types are significant in recent years, as well as the continuing emergence of energy storage and energy efficiency technologies. All of this new growth is supported by adaptive market rules, stakeholder process, partnerships with industry groups and collaboration with members, state and federal agencies and commissions. With the emerging Smart Grid technologies, the U.S. electrical grid will evolve into a highly advanced, automated and interconnected network. Taking full advantage of renewable sources while dealing with the reliability challenges of the new resources will require a significant change in many aspects in power industry.

The overview of the efforts to promote renovation and the ongoing and future renewable energy in PJM footprint is presented in this paper. The current state of art renewable energy development in operation and planning will also be discussed. Some renewable related projects such as on-going renewable integration studies, energy storage batteries and demand response will shed the light of the future trend.
\end{abstract}

Keyword: Renewable energy, smart grid, energy market.

\section{INTRODUCTION}

The growth of renewable energy is significant worldwide in recent years. The integration policies, regulations, technologies and associated standards are also developed or in the developing phase. Unlike the depending on some factors which industry has rarely been challenged before.

As one of the largest regional transmission organizations in the world, PJM Interconnection coordinates the flow of the wholesale electricity in 13

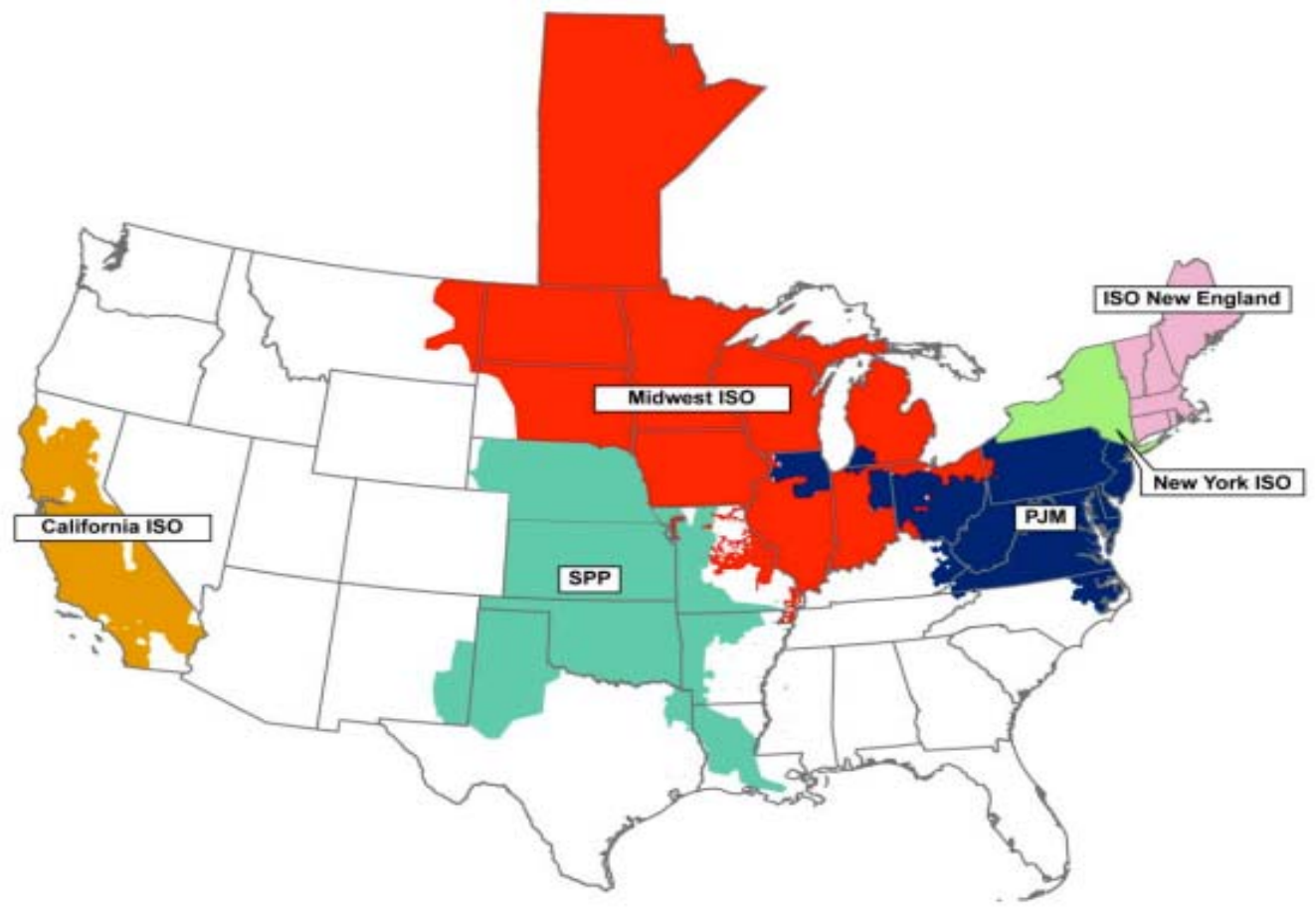

Figure 1: Map of ISO/RTOs in United States.

conventional generation, the nature of the renewable energy makes the process more complicated

*Address correspondence to this author at the IEEE Senior Member, PJM Interconnection, USA; Tel: 6106664640; Fax: 6107284868;

E-mail: fanz@pjm.com
States and Washington D.C. in Eastern Interconnection in US. Figure 1 shows the footprint of current ISO/RTOs in United States. The generation capacity of PJM is about 185,000 MW with 158,000 MW peak demand. It serves 60 millions of people in the east part 
Table 1: Grid Comparison Among ISO/RTOs in US

\begin{tabular}{|c|c|c|c|}
\hline ISO/RTO & Installed Generation (MW) & Miles of Transmission Lines & Population (in millions) \\
\hline \hline CAISO & 57,124 & 25,526 & 30 \\
\hline ISO-NE & 32,000 & 8,130 & 14 \\
\hline MISO & 148,456 & 57,453 & 42 \\
\hline NYISO & 37,416 & 10,877 & 19 \\
\hline PJM & 184,895 & 56,499 & 60 \\
\hline SPP & 66,175 & 50,575 & 15 \\
\hline
\end{tabular}

of US and has more than 750 members from the industry [1].

Table 1 shows the comparison among the six similar organizations in US.

The signs of growth in greener energy on the PJM grid and within the wholesale power markets are blooming in many ways. The growth can be seen in the more than 139 percent increase of solar energy produced over the previous year, the preponderance of proposed wind generation projects, the growth of demand response participation and offerings, as well as the continuing emergence of energy storage and energy efficiency technologies. Figure 2 shows the amount of megawatt-hours of renewable energy by fuel source produced in PJM for each year since tracking began in late 2005 [2].

This paper is structured by the functionalities of the company. Renewable developments impact on the system operation, energy market and grid planning will be discussed. The paper will summarize the activities and efforts PJM is undertaking. Section II highlights the renewable projects development in PJM area. The integration challenges in operation, market and planning are discussed in section III. Several PJM's projects and studies are presented in the following section. The conclusion is drawn in the end for future discussion.

\section{RENEWABLE DEVELOPMENT IN PJM}

Though the renewable generation provides less than 4 percent of total electricity in PJM, there has been a large number of proposed renewable entering the PJM queue and the penetration level will be around $10 \%$ in the next 5 years. The pie chart on the left in Figure 3 shows the current generation fleet in PJM. And significant renewable generation interconnection requests can be seen from the right side pie chart [3].

State Renewable Portfolio Standards (RPS) require entities that serve load do so using various eligible resource types including wind, solar and other renewable-powered generation technologies. States in the PJM region have a variety of RPS definitions and targets. Overall, approximately $135,000 \mathrm{GWh}$ of renewable energy, or approximately 14 percent of PJM's annual net energy output would be required from renewable resources in order to meet the aggregate of various state RPS targets by 2026 .

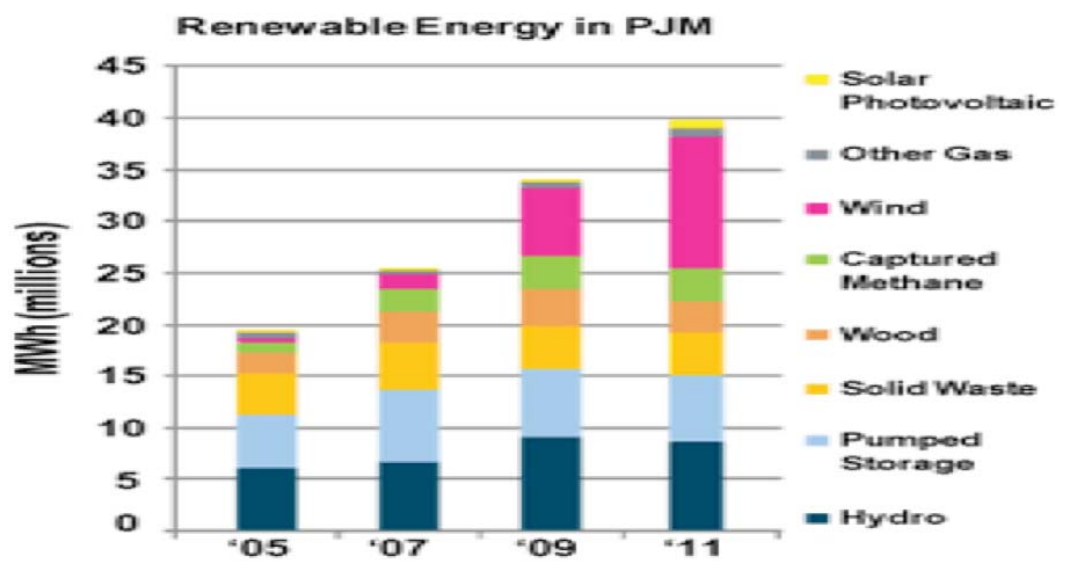

Figure 2: Renewable Energy Development in PJM. 

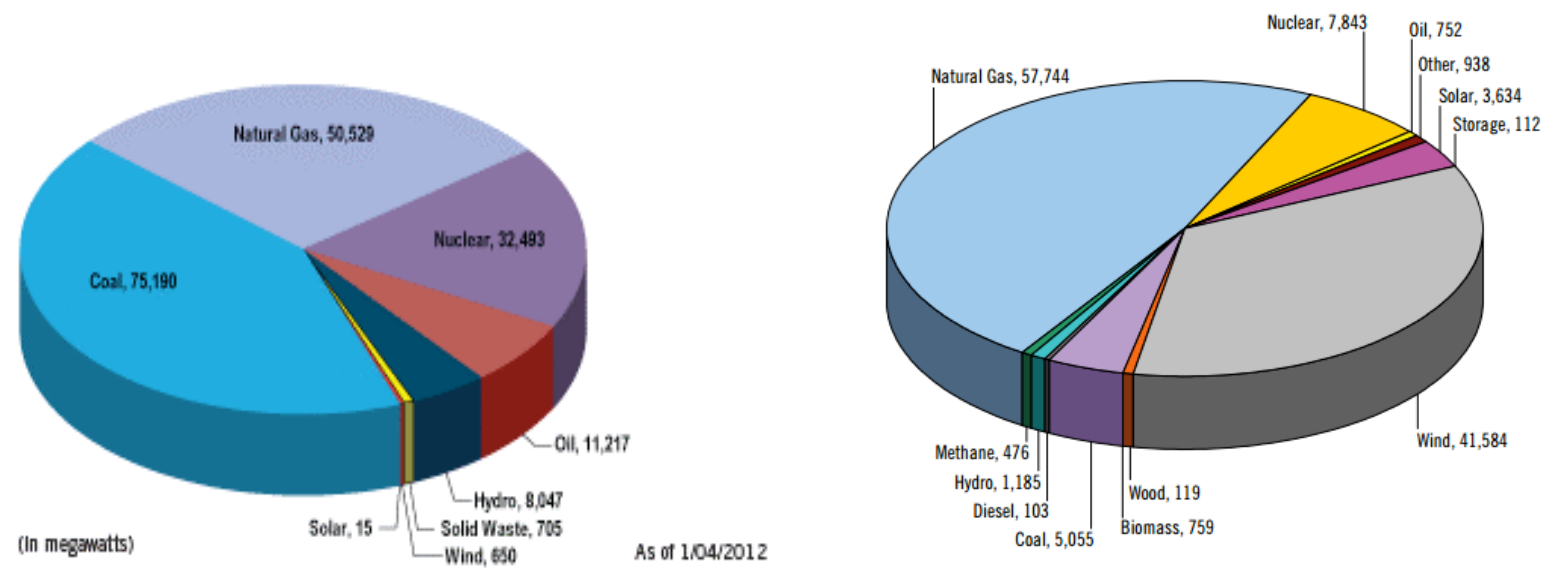

Figure 3: PJM Generation Fleet Pie Chart and Projected Generation Request.

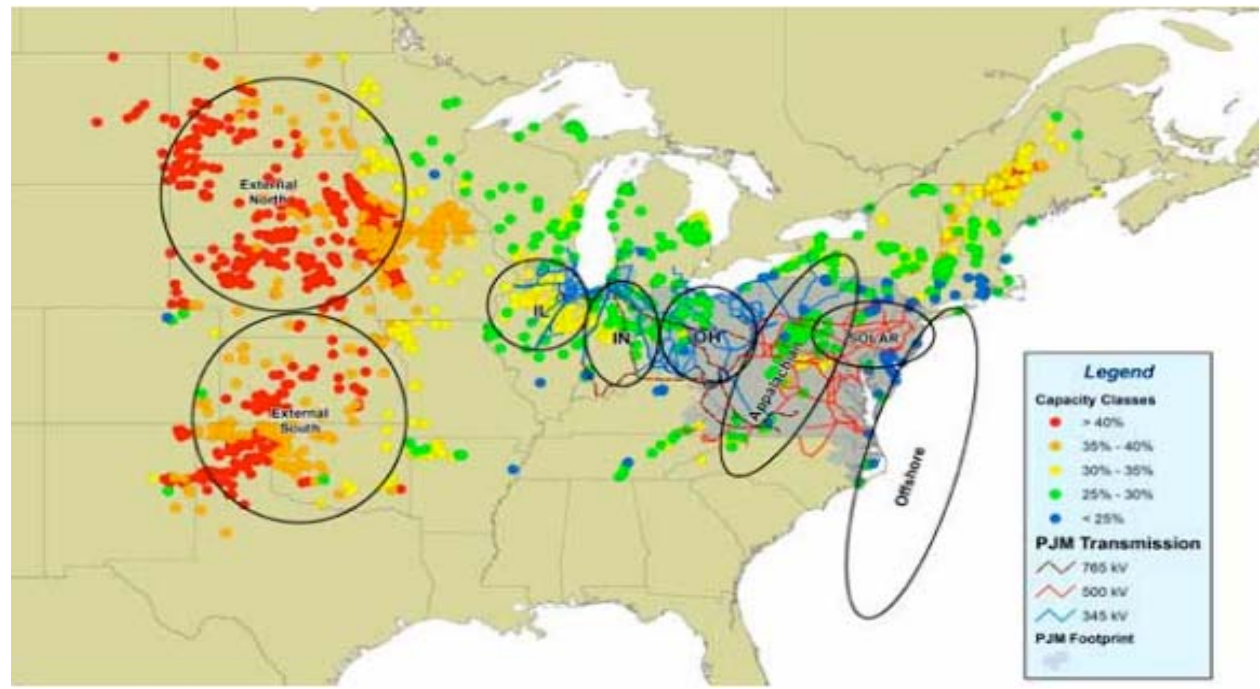

Figure 4: U.S. DOE NREL Overlay of Favorable Wind Sites in PJM.

DOE report as shown Figure 4 summarized the potential onshore and offshore sites for wind generation in PJM. [4] There are approximately 5,500 $\mathrm{MW}$ of current wind generation in PJM and another 40,000 MW requesting planning studies.

The installed solar power capacity is more than 1,000 MW in PJM which reflect the rapid growth of the solar power for the past couple years. The amount of solar power has doubled in each of the past two years and the number of new solar projects continues to grow. Figure 5 shows the installed solar generation by county in PJM region. New Jersey is one of the fastest growing regions for solar photovoltaic in the United States and is the second in terms of installed capacity.

The PJM renewable Energy Dashboard provides a snapshot of green and alternative energy on the PJM grid today and tomorrow. The Figure 6 shows how many megawatt-hours of renewable energy were produced in 2011 and cumulatively since tracking began in 2005. It also shows the percentage change between 2010 and 2011 [2].

\section{RENEWABLE ENERGY INTEGRATION CHALLENGES}

Variability and unpredictability of renewable energy require specific changes in planning, market and operation during integration. Task forces from scheduling to cost allocation regarding these issues were set up and ongoing in PJM. This section will highlight some of the outputs from those works.

\section{A. Planning Studies/Projects}

Wind and solar powered facilities which now are growing percentage of interconnection requests constitute a significant driver of regional transmission expansion needs. Feasibility, System Impact and Facilities Studies ensure that new capacity resources 


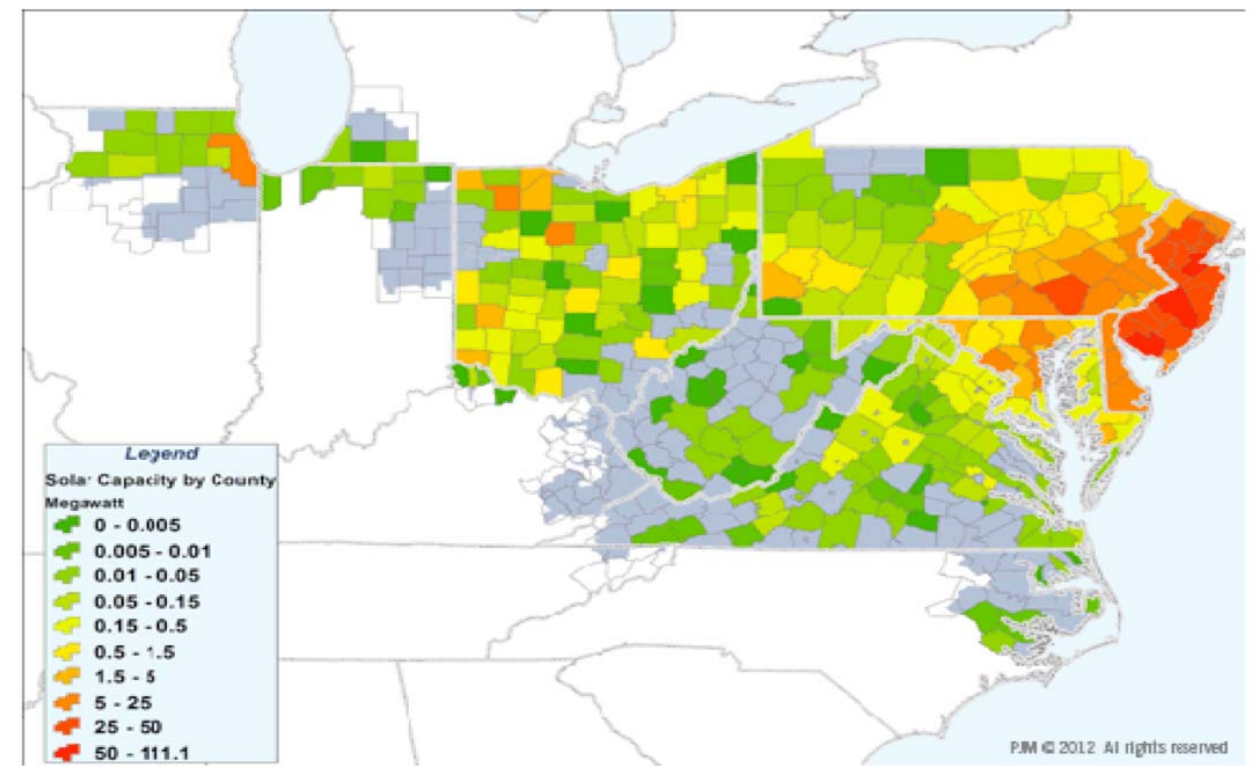

Figure 5: Solar Installation in PJM.

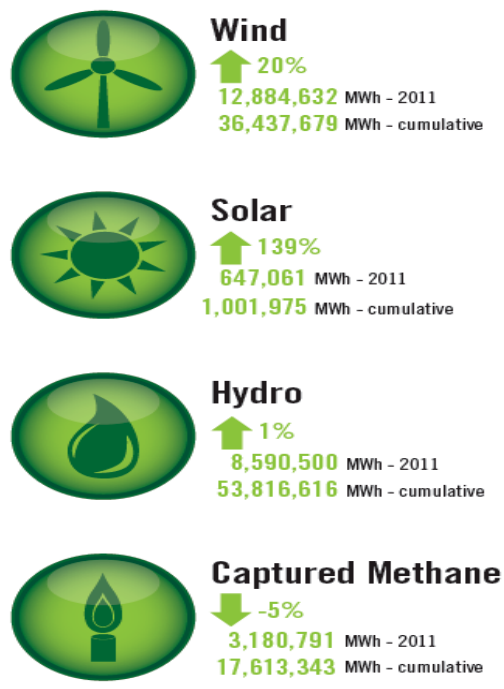

Figure 6: Renewable Energy in PJM.

interconnect without violating established NERC criteria [5].

In addition to all facets of the standard stability study scope, wind generators will be studied during their impact study stability analysis for compliance with the Low Voltage Ride Through Criteria (LVRT). The LVRT criteria tests the ability to the wind farm generator to maintain operation and interconnection with the system during events that cause extremely low voltage transients as measured at the high side of the transformer that steps up the Wind Farm's voltage to the transmission system. Peak load conditions are the most stressful for maintaining system voltage so this analysis will be conducted on a peak load power flow

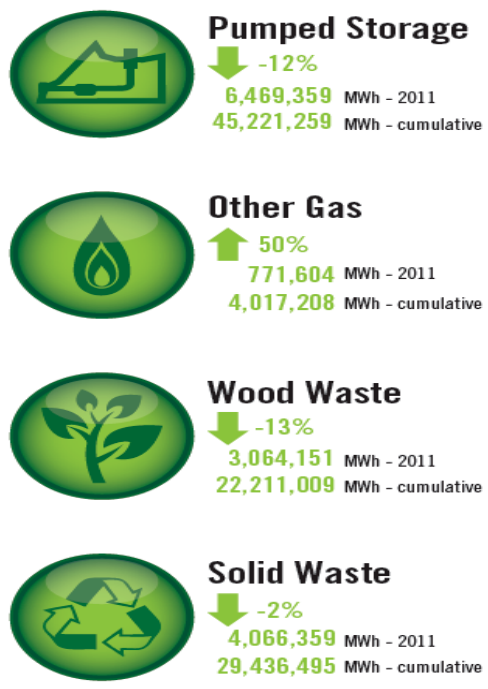

model. Based on the results of the standard stability analysis, PJM will determine the most critical three phase faults with normal clearing and phase to ground faults with delayed clearing. The wind generator will be required to maintain its power output to the system following three phase faults cleared in up through 9 cycles and that produce a voltage as low as zero at the high side of the GSU. Actual clearing times plus applicable margins will be used, which may be less than 9 cycles and high side GSU voltages may be somewhat greater than zero. Also the wind farm must maintain output to the system following the most critical phase to ground faults with delayed clearing, using actual clearing times. Applicable clearing time margins will apply to the LVRT test. 
Stability tests will be conducted on a system model with the GSU modeled and zero generator reactive power output with unity power factor. When power flow analysis does not model the generator step up transformer, the zero generator reactive power output is applied at the collector bus. This base case and the stability analysis will establish power factor or reactive power delivery requirements only if impact study analysis is conducted that demonstrates that the safety or reliability of the system is impacted by the lack of the requirement. System transient, oscillatory, or voltage instability during any phase of the impact study is evidence of system safety or reliability impact. For such results, the least cost remedy that considers system protection, transmission upgrades, or reactive requirements will be determined and specified.

In the event that the transient or voltage instability affects the wind project, for example when long radial interconnection facilities cause the inability of the wind facility to remain stably interconnected, the wind project will be notified and be requested to provide project design remedies. PJM's analysis of possible remedies will be limited to specifying the size of dynamic reactive device or increased transmission interconnection capacity if such a remedies are sufficient.

\section{B. Energy Market}

The wide scope of PJM's operations and markets provides ample opportunities for variable energy resources to conduct business. PJM's capacity and energy markets continue to attract significant volumes of renewable generation interconnection requests.

In the Real-time Energy Market, there are no penalties levied on generation for scheduling deviations. Instead, all generation can buy power at market prices to meet previously arranged schedules, as for example, if wind output drops. Wind generation also receives market-based revenues if wind project deliveries exceed scheduled amounts.

Variable resources benefit from the short scheduling intervals of PJM's market. Generators of any type can self-schedule with 20-minutes notice; PJM typically approves a dispatch case and sends out new dispatch signals every four to five minutes. This helps reduce the need for regulation service to deal with changes in load within each hour.

In Day ahead market, renewable generation resources that are capacity resources who participate in the Reliability Pricing Model (RPM) markets shall meet the must offer requirement by either selfscheduling (Availability = Must Run) or may allow the Day-ahead Market to schedule by offering the unit as a dispatchable resource (Availability $=$ Economic). The hourly Day-ahead self-scheduled values for intermittent resources may vary hour to hour from the capacity obligation value. A generation offer that is accepted for the Day-ahead market automatically carries over into the balancing market. Day-ahead generation offers should reflect the owner's wind forecast for that hour and what the unit will be expected to produce.

Renewable resources have the ability to earn revenues by participating as capacity resources in PJM's capacity market, the Reliability Pricing Model (RPM). Because of the intermittent nature of these resources, PJM's capacity valuation procedure allows wind to receive capacity credit on a rolling three-year average of actual performance over the previous three summers. If they have been in operation for less than three years, wind and solar projects receive a class average value - for wind, 13 percent of nameplate capability and for solar photovoltaic facilities, 38 percent of $A C$ rating.

\section{Operation (Forecast/Reserve)}

Like load forecasting, renewable forecasting especially wind forecasting will play a very important role in operation. With penetration of significant amount of wind into the grid, the integration and operation will largely depend on the accuracy of the wind power forecast. PJM started wind forecasting in 2009. Currently, the forecasting consists of short term $(<6 \mathrm{Hrs})$, medium term $(6-42 \mathrm{Hrs})$, long term (42$120 \mathrm{Hrs})$ and ramp forecast $(<6 \mathrm{Hrs})$. Short term forecast is used to evaluate current day congestion and to ensure sufficient generation units are available to respond to real time or coming hours fluctuations. Medium term forecast is used to predict day-ahead congestion and to ensure enough generation resources are scheduled to meet the load and reserve requirements. Aggregated data from the service is made available to members and is used to help determine the next-day unit commitment to ensure there are sufficient reserves. The forecasting also was designed to encourage participation by wind resources in the Day-Ahead Energy Market. Long term forecast may be used for weekend and holiday conditions. Wind ramps become another key factor among wind forecasts due to the magnitude and speed they can occur. One lesson has been learned in ERCOT in 


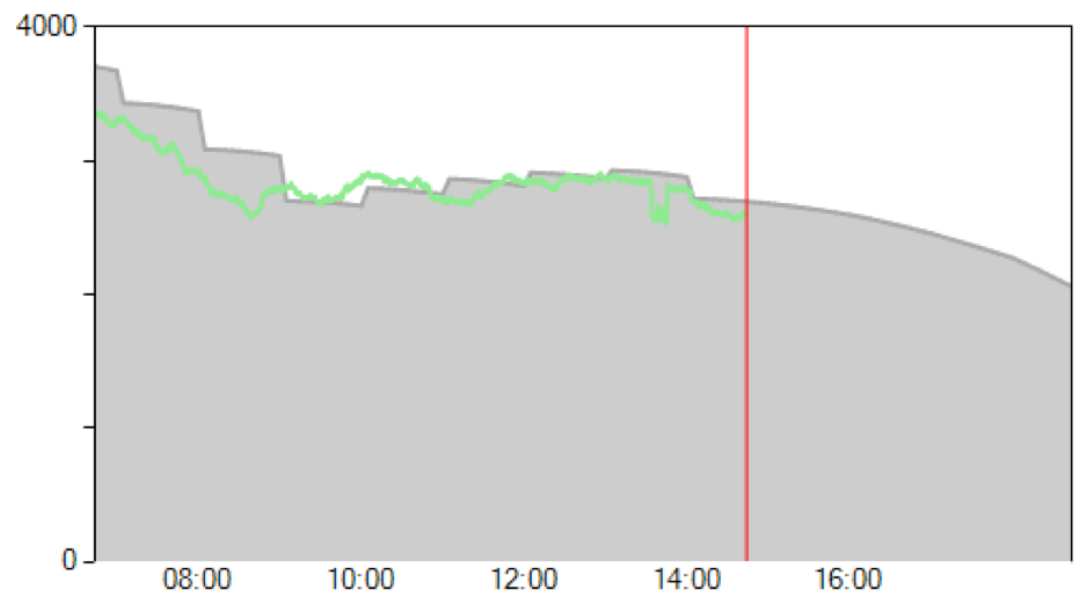

Figure 7: Wind Forecast and Real-time Measurement in PJM.

2008. PJM is in developing stage for a separate ramp forecast. Like most utilities and RTOs in the United States, PJM pays for its variable generation forecasting system without passing along the costs to generator owners. Figure 7 displays both instantaneous power (in megawatts) being produced and forecasted power for every five minutes. It is updated hourly. The data is measured at each wind farm every minute and then is aggregated for this tool. Dispatchers use this display to monitor trends in wind power production.

For individual wind turbines, PJM requires turbine capacity, minimum/ maximum wind speed, manufacturer power curves, geographic location, hub height, ambient temperature operating limits, and information on installation of cold weather packages. Along with these turbine-specific requirements, PJM also requires that the initial project data required include aggregate historic power output, meteorological and outage data, and the aggregate reactive capability curve. For wind plants as a whole, PJM requires the real-time aggregate wind plants' MW output. At least one meteorological tower (or wind speed and direction from selected wind turbine anemometers and wind vanes) with wind speed and wind direction data is required, temperature and pressure data is preferred, and humidity data is accepted.

As more variable generation is added to the grid, different grid operators have adjusted existing practices, or implemented new practices in regulation such as Minute-to-Minute, Intra-Hour variation and Day Ahead forecast. [6] Regulation addresses the fast and frequent variations in load and generation that contribute to energy imbalance. Additional regulation needed is equal to about $1 \%$ of the nameplate capacity of a $100 \mathrm{MW}$ wind plant.
PJM's regulation requirement is determined in whole MW for daily on-peak (between 5:00 a.m. and 11:59 p.m.) and off-peak (midnight to 4:59 a.m.). PJM's on-peak regulation requirement is equal to $1 \%$ of the daily forecasted peak load, and the off-peak regulation requirement is equal to $1 \%$ of the daily forecasted valley load. PJM sends two regulation signals. The first is the assigned hourly regulation quantity, in MW, that is cleared from the regulation market and is sent on a 10 -second scan rate. The second signal is Reg A, which is the real-time instantaneous resource owner fleet regulation signal that moves regulating resources in the regulation owner's resource fleet within the fleet capacity, and is sent on a 2-second scan rate.

\section{RENEWABLE PILOT PROJECTS IN PJM}

PJM embraces innovation and fosters collaboration with other key players in the power industry to explore new and emerging technologies that could shape the future of the industry. Through this effort, PJM uses information gained through pilots to enhance the quality of its wholesale electricity markets.

\section{A. Wind Integration Study}

PJM is conducting two integration studies to examine the impact of renewable resources on the planning and operation of the transmission system. One study is assessing the impact of large-scale renewable energy integration on operations, planning and markets. The other study is evaluating the impact of state renewable portfolio standards (RPS) on the planning of the high-voltage transmission system at the 345-kilovolt level and above. The study will show what the PJM system could look like in 2021 and 2026 in terms of the transmission enhancements needed to meet the RPS standards of the PJM states. 
Driven by fast increasing wind penetration in RTO footprint due to member state RPS/AEPS, PJM intends to perform a comprehensive renewable (mainly wind, but including solar) power integration study to investigate and address a range of important and contemporary technical issues. The goals of this "PJM Wind Integration Study" (PWIS) will be to determine, for the PJM balancing area, the operational, planning, and market effects of large-scale integration of wind power as well as mitigation/facilitation measures available to PJM and make recommendations for the implementation of such mitigation/facilitation measures.

The project is undergoing and had several deliverables already including resource profiles, scenario development and other lessens and learned. The goal is to identify the potential challenging time periods of operations created or exacerbated by the variability and unpredictability of wind power; and formulate of recommendations for potential corrective activities that may be taken in order to mitigate these adverse impact will be highlighted by 2013 .

\section{B. Energy Storage Pilots}

A one-megawatt (MW) array of lithium-ion batteries provided regulation service in the PJM market for several years. The battery facility, housed in a trailer on the PJM campus, was owned by AES Energy Storage, a subsidiary of The AES Corp., a PJM member. This system completed the certification testing for regulation, similar to a generating unit, and has been in use since that time, with high demonstrated levels of availability. The Project is paid and settled as a regulating resource in the ancillary services market. The responses of this battery to the market signal are shown in Figure 7. A much larger battery facility, 32MW AES Laurel Mountain in West Virginia, went into operation in 2011 in conjunction with a 98-MW wind farm. The battery facility helps PJM quickly balance variations in load to regulate frequency as an alternative to adjusting the output of fossil-fuel generators; it is capable of changing its output in less than one second. In response to PJM requests to balance the grid, the battery unit can supply power into the grid by discharging its batteries or store excess electricity from the grid to charge its batteries.

A new stakeholder group within PJM, the Regulation Performance Senior Task Force, is looking at the ability to provide better quality regulation and to send more rapid regulation signals to more flexible resources, such as storage technologies. The task force is looking at a compensation model and incentives to better recognize the value of the instantaneous response capability of these resources.

Also being evaluated at PJM is thermal storage, using a large electric water heater that responds to grid needs when it receives pricing and regulation signals from PJM dispatchers.

Vehicle battery storage using plug-in hybrid electric vehicles (PHEVs) connected to the grid is another storage technology that is being evaluated. Offpeak electricity from the grid could charge PHEVs, shifting load to the night-time hours, while PHEVs also could provide regulation services to the grid in the daytime

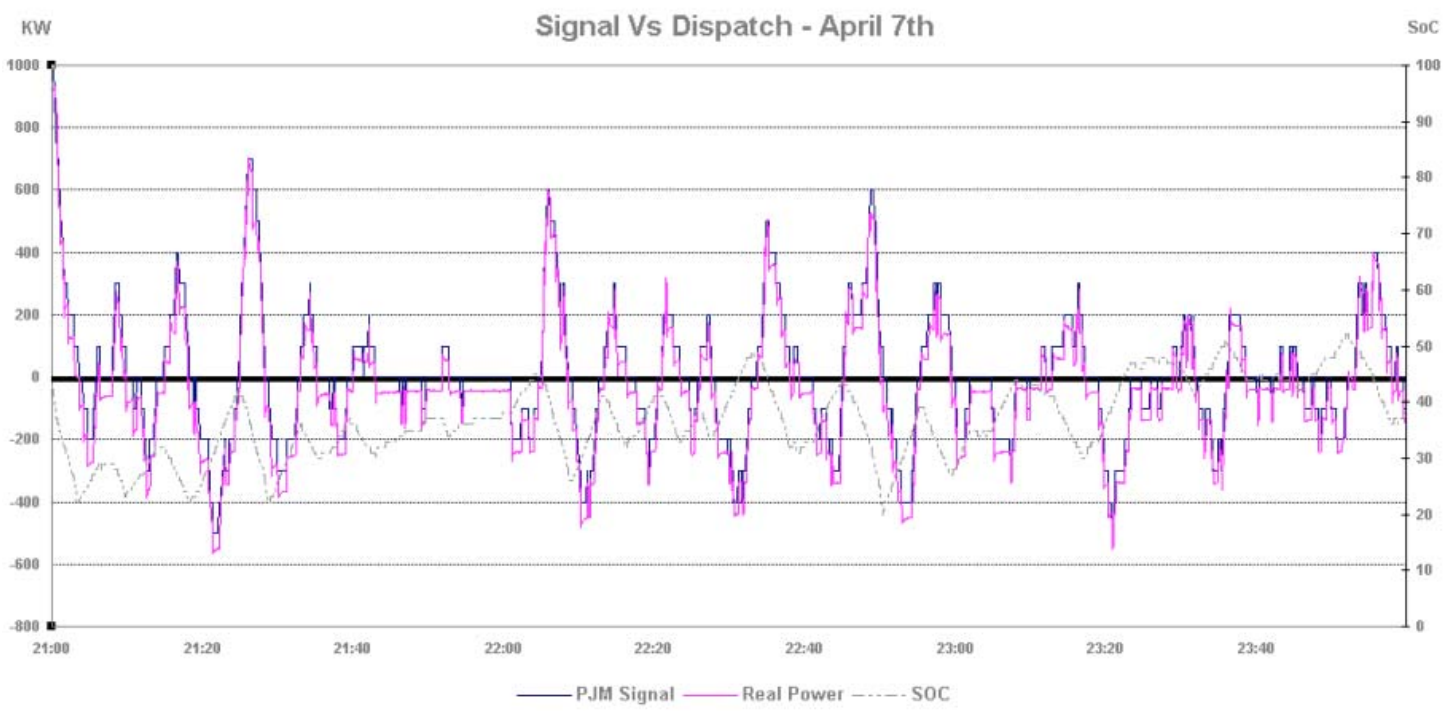

Figure 8: Response to Regulation Market Signal. 
hours. PJM is part of two consortiums - the University of Delaware's Mid-Atlantic Grid Interactive Car Consortium (MAGICC) and The Ohio State University's SMART@CAR - to demonstrate and evaluate this vehicle-to-grid (V2G) approach.

\section{Demand Response}

Demand response allows consumers to respond to wholesale electricity prices by curtailing consumption while continues to capture value in the energy marketplace. Two new product offerings in PJM for the capacity market enable demand responders to participate year-round and for expanded periods of time. Participants in demand response in PJM's Energy, Capacity, Synchronized Reserve and Regulation markets are paid for selling back the electricity they would have used.

Demand response is seen as more green-friendly because reducing and/or shifting electricity use translates to reducing emissions. The majority of registered demand-response sites reduce electricity use during peak periods, while a minority of sites uses on-site generation, subject to state environmental rules, to support reduction.

As of December 2012, 2,259 megawatts (MW) were registered to participate in economic demand response and approximately $11,523 \mathrm{MW}$ were registered to participate in emergency demand response programs for the upcoming 2012/2013 planning year. (The amount registered in economic demand response is nearly equivalent to the amount of electricity needed to power the greater Atlantic City area during a peak period.) The growth for demand response participation in PJM capacity market is clearly shown in Figure $\mathbf{9}$. These two programs enable participants to reduce load when appropriate for the participating site or needed for reliability. Participants value the opportunity to reduce power use and save money.

Any tool that helps to balance electricity supply and demand without having to find new supply (generation) supports a greener grid. One conceptual seed budding on the grid is Price Responsive Demand (PRD), a natural evolution of demand response. Price Responsive Demand allows the grid to benefit from the development of time-sensitive retail electricity rates and the installation of advanced meters.

\section{CONCLUSION}

Recognizing the potential impact of a significant infusion of new renewable energy sources not only on PJM but on the Eastern Interconnection as a whole, PJM acted as a catalyst in bringing together the transmission planning authorities across the interconnection to discuss how to create an interconnection wide planning framework. The outcome was the formation in 2009 of the Eastern Interconnection Planning Collaborative (EIPC), which is using the existing regional transmission plans of these industry groups as the basis to conduct transmission analyses for the interconnection as a whole. These analyses will address the impact of large amounts of variable energy resources that are expected to come on line in the future.

Flexible resources will be needed to offset the impacts of variable generating resources. Fundamentally, the transparent nature of wholesale

\section{Demand Response Resources Offered in PJM Capacity Auction (includes Energy Efficiency)}

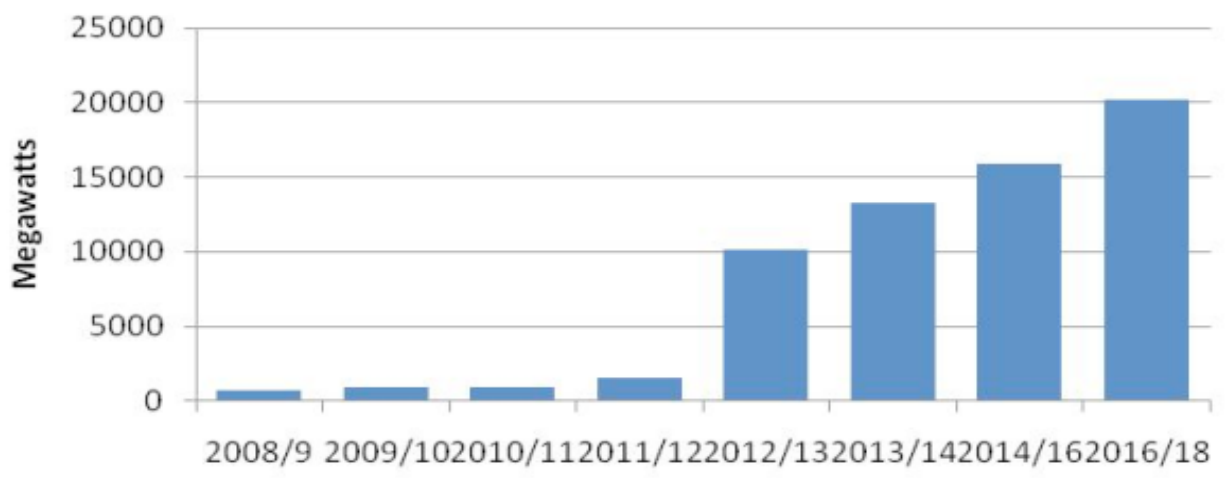

Figure 9: Demand Response Resources in RPM. 
markets facilitates efforts in support of a greener grid. Grid interconnection standards will need to be updated to ensure reliability with greater market penetrations.

Increasingly limited future supply will be partially offset by technology innovations in alternative renewable energy resources. The potential services delivered to the grid from those resources in PJM are capacity operating reserves and frequency regulation. This requires smart dispatch tools to fully utilize those resources. The system wide improvements and accommodations on hardware and software will be needed for tracking and controlling the high penetration of distributed generation.

\section{REFERENCES}

[1] Map of PJM territory served. PJM Interconnection; 2012: Available from: http://www.pjm.com/about-pjm/who-weare/territory-served.aspx
[2] Renewable Energy Dash Board, PJM Interconnection; Available from: http://www.pjm.com/about-pjm/renewabledashboard.aspx

[3] Book 1: PJM 2011 RTEP in Review. PJM Interconnection; 2012: Available from: http://www.pjm.com/documents/ reports/rtep-documents/2011-rtep.aspx

[4] Eastern Wind Integration and Transmission Study; 2011 Available from: http://www.nrel.gov/electricity/transmission/ eastern renewable.html\#ewits

[5] PJM Manual 14A Generation and Transmission Interconnection Process, PJM Interconnection; Aug 23, 2012: Available from: http://www.pjm.com/ /media/ documents/manuals/m14a.ashx

[6] PJM Renewable Integration Study (PRIS) Reports, PJM Interconnection; 2012: Available from: http://www.pjm.com/ committees-and-groups/task-forces/irtf.aspx 